\title{
ADAMS and ANSYS based Mechanism Optimization of Multifunctional Sprayer and Performance Test
}

\author{
Xinxue Zhao ${ }^{1,2}$, Xuemei Liu ${ }^{1,2}$, Jin Yuan ${ }^{1,2}$, Rongkang Chen ${ }^{1}$ \\ 1. Department of Mechanical and Electronic Engineering \\ Shandong Agricultural University \\ Taian, China \\ zhaoxinxue1980@163.com,lxmywj@126.com,jyuan@sdau.edu.cn \\ 2. Key Laboratory of Horticultural Machinery and Equipment \\ Shandong Province \\ Taian, China
}

\begin{abstract}
For significant differences in plant morphology at different growth stage after tobacco transplanting, using single boom sprayer leads to poor disease and pest control. This paper designed a multifunctional sprayer, to conduct boom spray to seedling stage, and to conduct tunnel spray to maturity stage. First introduced the overall structure of the sprayer, applied ANSYS modal analysis technology to optimize the deformation mechanism, and combined with ADAMS dynamic simulation to verify the reliability of the design. Then according to the designed parameters, the sprayer prototype was built. Modal test of deformation mechanism and field test of sprayer were carried out. Modal test showed that the first natural frequency of deformation mechanism was $9.8 \mathrm{~Hz}$ after optimization, the deviation of frequency between analysis and modal test was less than $10 \%$. Field test showed in seedling and maturity stage of tobacco prototype's working efficiency was closed to 1.225 and $0.687 \mathrm{hm}^{2} / \mathrm{h}$, leaves liquid coverage reached $89.7 \%$ and $92.8 \%$ respectively, and almost no damage to tobacco leaves.
\end{abstract}

Keywords-multifunctional sprayer, mechanism optimize, modal analysis, finite element analysis, dynamic simulation

\section{INTRODUCTION}

There are 68 kinds of infectious diseases, and more than 200 pests for China's tobacco. Throughout each growth stage after transplanting, pest control is mainly integrated with chemicals in tobacco cultivation process. Other studies, [1, 2, 3], showed boom sprayer was one of the most common pesticide machinery used in plant protection, because of high efficiency, good spraying quality, large working width, played a leading role in tobacco production.

Fengfound that tobacco cultivation agronomy required wide line spacing and large plant spacing. Beginning of low seedlings, the plant structure of tobacco changed constantly in field [4]. Gradually tobacco formed canopy layer with tall plants, wide leaves, vertically overlapping, and mutual occlusion. To ensure good control effect of pesticides, considering the differences of target crops' plant structure, selected appropriate spray ways and machinery, according to the morphological characteristics of different growth stages. In this way could help to ensure enough liquid deposition of the canopy's upper and lower, inner and outer, leaves positive and negative, increase utilization effective of pesticides, and reduce environmental pollution.

Currently we mainly use the boom spray mode for plant protection operation, which has no problem in tobacco seedling stage. But Dieter and Wang [5,6] found that in the maturity stage with dense and mutual occlusion, if still used top-down boom spraying, because the upper tobacco leaves block, making the lower tobacco cannot get enough liquid deposition and the upper layer of excess liquid drop into soil, contaminating farmland environment. Some studies, [7, 8, 9], showed that should take tunnel operation mode in the maturity stage.

For significant differences in plant morphology at different growth stages after transplanting, using traditional boom sprayer led to poor spray quality and low utilization of pesticides, when the tobacco formed tall and high density canopy. In response to these problems designed a multifunctional sprayer, to conduct boom spray to seedling stage, and to conduct tunnel spray to maturity stage, had important practical significance. This paper introduced the overall structure of the multifunctional sprayer, applied ANSYS modal analysis technology to optimize the deformation mechanism, which the key components of the sprayer, combined with ADAMS dynamic simulation to verify the reliability of the design. Finally, we analysed the operating performance of multifunctional sprayer by field trials.

\section{STRUCTURE OF MULTIFUNCTIONAL SPRAYER}

\section{A. Overall structure}

Multifunctional sprayer consists of crawler walking frame, lifting mechanism, deformation mechanism, collapsed mechanism, and liquid spray system and collection circulatory system, Fig. 1. Lifting mechanism of spray frame is composed of lifting frame, guide wheel, chain guide and electric putter, fixing in front of the walking frame. The height of spray frame is changed by lifting electric putter. Deformation mechanism comprises track frame, connecting frame, drive motor, drag chain, electric putter and flank spray frame, connecting frame 
is moved in the horizontal direction through the drag motor and chain, and deformation electric putter makes flank spray frame rotate around the connecting frame. Collapsed mechanism is made up of connecting ring lever and electric putter. Liquid spray system includes pump, spray bar, line, dispensing valve, the tank and spray nozzle group. The residue collection cycle system comprises filter, collection tank, the collection tube, level switch and recycling pump.

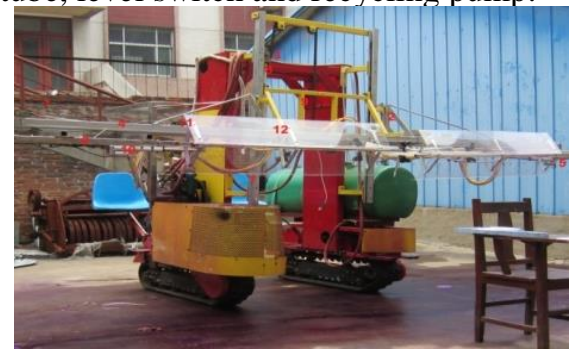

Fig. 1. Structure of multifunctional sprayer

\section{B. Two working modes and conversion}

In pest control process, multifunctional sprayer need to convert working mode according to the crop patterns of life cycle, to ensure good control of pesticides. Multifunctional sprayer has boom and tunnel two kinds of spray modes.

Boom spray mode: When spraying chemical pesticides on seedling tobacco, driving lifting electric putter to move the spray frame in the vertical direction to $0.2 \sim 0.3$ meters from the top of tobacco. Connecting frame is moved in the horizontal direction through the drag motor and chain, which put the flank spray frame to the both ends of the track frame. Then driving deformation electric putter makes flank spray frame rotate $90^{\circ}$ to achieve the level stretch.

Tunnel spray mode: When spraying chemical pesticides on maturity tobacco, driving lifting electric putter move the spray frame in the vertical direction to the top of sprayer. Connecting frame is moved in the horizontal direction through the drag motor and chain, which put the flank spray frame to the middle of the track frame. Then driving deformation electric putter makes flank spray frame rotate $90^{\circ}$ to realize the tunnel collapsed.

\section{OPTIMIZE DESIGN OF SPRAYER DEFORMATION MECHANISM}

Before The sprayer must to meet the spray needs of tobacco in different growth stages by changing the operating mode. But the conversion between boom and tunnel spray mode is mainly achieved through the deformation mechanism. Therefore, the stability and strength of deformation mechanism is the focus of the design. Qiu found that spray boom was weak damping elastomeric[10]. The acceleration produced by uneven road would result in elastic deformation of the boom, which one of the main reasons caused the decline of spray deposition uniformity. The structure of sprayer is mainly composed of hollow tube with different sectional shape and thickness. The length of spray boom is 7.2 meters long after flattening. If the sectional dimensions and thickness of tube were inappropriate choice, which would make the natural frequency of deformation mechanism approaching to the excitation frequency of walking frame, sprayer easily resonated with walking frame. If resonance occurred, would increase the elastic deformation of mechanism and affect the spray quality. Therefore this section first determined the structural parameters of deformation mechanism in boom and tunnel operation mode, according to the tobacco ecological parameters of each stage. Then we optimized the deformation mechanism by ANSYS finite element modal analysis and evaluated the reliability by ADAMS dynamic simulation analysis. By this way ultimately met the design requirements.

TABLE I. DESIGN PARAMETER

\begin{tabular}{|c|c|c|}
\hline Name & Boom spray & Tunnel spray \\
\hline Spray pressure(MPa) & \multicolumn{2}{|c|}{0.4} \\
\hline Capacity kits(L) & \multicolumn{2}{|c|}{350} \\
\hline Nozzle type & Sector & Conical \\
\hline Spray angle $\left({ }^{\circ}\right)$ & 110 & 80 \\
\hline Working ridge & 7 & 3 \\
\hline Maximum working width $(\mathrm{m})$ & 8.4 & 3.6 \\
\hline Nozzle Install spacing $(\mathrm{m})$ & 1.2 & 0.25 \\
\hline Walking speed $(\mathrm{m} / \mathrm{s})$ & 0.47 & 0.53 \\
\hline Working efficiency $\left(\mathrm{hm}^{2} / \mathrm{h}\right)$ & 1.2 & 0.68 \\
\hline
\end{tabular}

\section{A. Structural design of deformation mechanism}

When spraying liquid, the sprayer must fulfil the needs of seven rows of boom and three rows of tunnel spraying. Based on the design parameters shown in Table I, determined the level of structure parameters of horizontal sliding frame and flank spray frame, which accomplished working mode conversion, to suit the job requirements of different modes. Horizontal sliding frame and flank spray frame were made of steel tube with different sectional dimensions and thickness. Specific parameters of the components were shown in Table II. Fig. 2 showed that the structure of deformation mechanism before and after deformation.

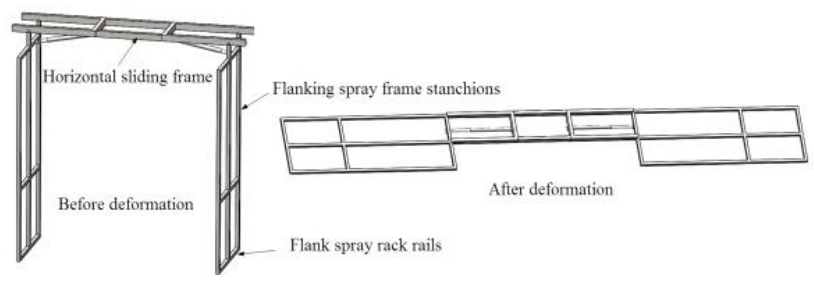

Fig. 2. Schematic view of deformation mechanism

\section{B. Modal analysis of deformation mechanism}

When the sprayer converted from boom to tunnel mode, the length of deformation mechanism was the longest and the elastic deformation was more serious, so we mainly analyzed the modal of boom mode. Because of the symmetry of the overall structure, when set up finite element model in the software ANSYS, we selected half of the deformation mechanism for analysis. The steel tube of horizontal sliding frame and flank spray frame in accordance with the parameters (Table II) was modelled, and the remaining nonmain tubes according to the actual structure were definition. In the model the density of steel tube was $7.9 \times 10^{3} \mathrm{~kg} / \mathrm{m}^{3}$, modulus of elasticity was $206 \mathrm{GPa}$, Poisson's ratio was 0.3 , and the cell type was $8 \mathrm{~mm}$ beam 188 . 
Using the Block Lanczos method to extract the first six natural frequencies and mode shapes, before optimization natural frequencies were $7.1,20.2,22.8,42.6,48.1,65.7 \mathrm{~Hz}$. Since crawler walking frame walking slowly, good stability and better low-pass filtering in field, its excitation generally less than $5 \mathrm{~Hz}$. When there was no suspension equipment between boom and sprayer frame, excitation caused by uneven road would directly pass to the boom. The first natural frequency of deformation mechanism was $7.1 \mathrm{~Hz}$ in boom spray, and neared to $5 \mathrm{~Hz}$, the boom was easy to produce large deformation during operation. So we need to optimize the deformation mechanism to enhance the dynamic stiffness of the boom, when its excitation was less than $5 \mathrm{~Hz}$. Taking into account the structure should not be a major change, this paper by varying the sectional dimensions and thickness of tube, increasing the quality of the boom to enhance the system's natural frequency. The dimensions and thickness after optimization obtained by finite element were shown in table 3 . Natural frequencies after optimizing were 10.5, 29.7, 32.2, $56.2,62.3,83.1 \mathrm{~Hz}$, effectively avoid the excitation range of 5Hz. First two modal shapes were shown in Fig. 3.

TABLE II. STRUCTURAL PARAMETERS OF DEFORMATION MECHANISM

\begin{tabular}{|c|c|c|c|c|c|c|}
\hline \multirow[b]{2}{*}{ Name } & \multirow[b]{2}{*}{$\begin{array}{c}\text { Length } \\
(\mathrm{mm})\end{array}$} & \multirow[b]{2}{*}{$\begin{array}{c}\text { Section } \\
\text { type }\end{array}$} & \multicolumn{2}{|c|}{ Before optimization } & \multicolumn{2}{|c|}{ After optimization } \\
\hline & & & $\begin{array}{c}\text { Sectional } \\
\text { dimension } \\
(\mathrm{mm})\end{array}$ & $\begin{array}{c}\text { Wall } \\
\text { thicknes } \\
s(\mathrm{~mm})\end{array}$ & $\begin{array}{c}\text { Sectional } \\
\text { dimension } \\
(\mathrm{mm})\end{array}$ & $\begin{array}{c}\text { Wall } \\
\text { thicknes } \\
\text { s (mm) }\end{array}$ \\
\hline $\begin{array}{l}\text { Horizo } \\
\text {-ntal } \\
\text { sliding } \\
\text { frame }\end{array}$ & 1500 & $\begin{array}{l}\text { Rectang } \\
\text {-ular } \\
\text { tube }\end{array}$ & $20 * 35$ & 1.5 & $25 * 35$ & 2 \\
\hline $\begin{array}{c}\text { Flank } \\
\text { spray } \\
\text { frame } \\
\text { rails }\end{array}$ & 800 & $\begin{array}{l}\text { Rectang } \\
\text {-ular } \\
\text { tube }\end{array}$ & $20 * 35$ & 1.5 & $25 * 35$ & 2 \\
\hline $\begin{array}{c}\text { Flank } \\
\text { spray } \\
\text { frame } \\
\text { stanchi } \\
\text {-ons }\end{array}$ & 1100 & $\begin{array}{l}\text { Square } \\
\text { tube }\end{array}$ & $15 * 15$ & 1 & $20 * 20$ & 1.5 \\
\hline
\end{tabular}
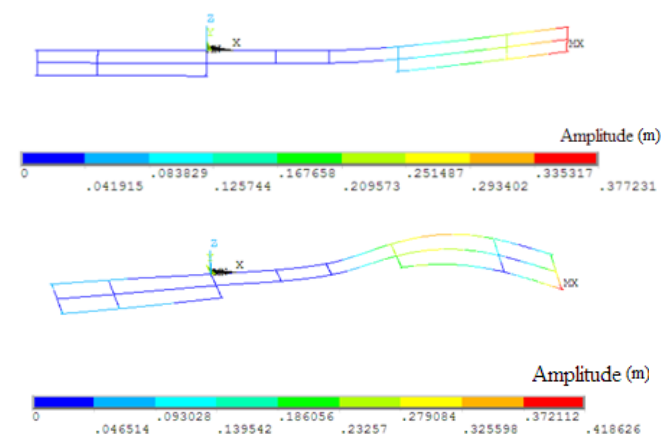

Fig. 3. First two mode shapes of boom by modal calculation

\section{ADAMS dynamic simulation}

Because the deformation mechanism by moving horizontal sliding frame and turning flank spray frame to achieve deformation, rotation reliability of flank spray frame was the focus of the design. Therefore, based on finite element modal analysis, we used dynamic simulation software ADAMS to simulate the rotation of deformation mechanism, analysis the equivalent stress of the components, and evaluate the reliability of the deformation mechanism.

We built up the solid model of deformation mechanism in 3D modelling software SolidWorks. Then we imported the model into ADAMS. In order to improve the efficiency and accuracy of analysis, without considering the influence of the liquid recovery and leaves toggle plate; only considering the impact of two parts' weight, when analyzed by ADAMS. At the same time the weight of the flank spray frame's panels was equivalent to the rod.

The simulation results showed the components of flank spray frame operated flexibly, moving parts didn't appear the phenomenon of interfere with each other, when the deformation mechanism from tunnel converted to boom spraying mode. During the rotation of flank spray frame, the maximum stress was concentrated in the hinges at the rail and stanchion, stanchion and electric putter. The maximum equivalent stress was $152 \mathrm{MPa}$ (Fig. 4), far less than the yield strength $310 \mathrm{MPa}$, and no permanent plastic deformation appeared. The components of deformation mechanism could meet the requirements of statics.

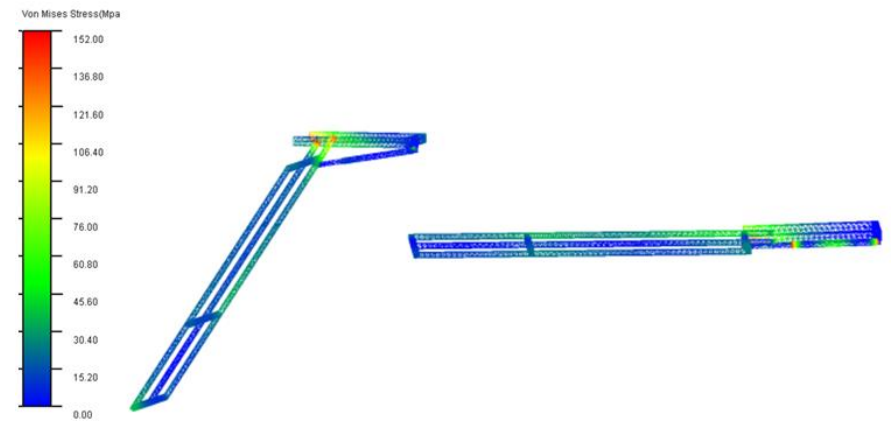

Fig. 4. Stress variation of components with flank spray frame around different angles

\section{MODAL TEST OF DEFORMATION MECHANISM}

We selected multi-point excitation and sentinel response method for modal test. The excitation signal was given by exciting hammer, and collected by the force sensor. Response signal was collected by acceleration sensor. The collected excitation and response signals amplified through the charge amplifier. Then we conducted fast Fourier transform in the dynamic signal analyzer and calculated the frequency response function. In order to eliminated random noise signal in sampling process, frequency response function was carried out for the average of five times, and ultimately determined modal parameters were shown in Table III

TABLE III. THE DATA OF MODAL TEST

\begin{tabular}{|c|c|c|c|}
\hline Order & $\begin{array}{c}\text { Test } \\
\text { frequency } \\
(\mathbf{H z})\end{array}$ & $\begin{array}{c}\text { Calculate } \\
\text { frequency }(\mathrm{Hz})\end{array}$ & $\begin{array}{c}\text { Frequency } \\
\text { deviation (\%) }\end{array}$ \\
\hline 1 & 9.8 & 10.5 & 7.14 \\
\hline 2 & 27.5 & 29.7 & 8.00 \\
\hline 3 & 33.9 & 32.2 & 5.01 \\
\hline 4 & 59.1 & 56.2 & 5.55 \\
\hline 5 & 65.1 & 62.3 & 4.30 \\
\hline 6 & 79.4 & 83.1 & 4.66 \\
\hline
\end{tabular}




\section{FIELD TEST OF MULTIFUNCTIONAL SPRAYER}

In order to evaluate the performance of multifunctional sprayer, field spray test was conducted in tobacco seedling and maturity stage. The purpose of test was aimed to obtain the parameters during the spray operation, such as walking speed, working efficiency, leaves liquid coverage and damage rate and so on. Through the test parameters assessed the operation quality and effectiveness of the sprayer. Field test cases of multifunctional sprayer were shown in Fig. 5.

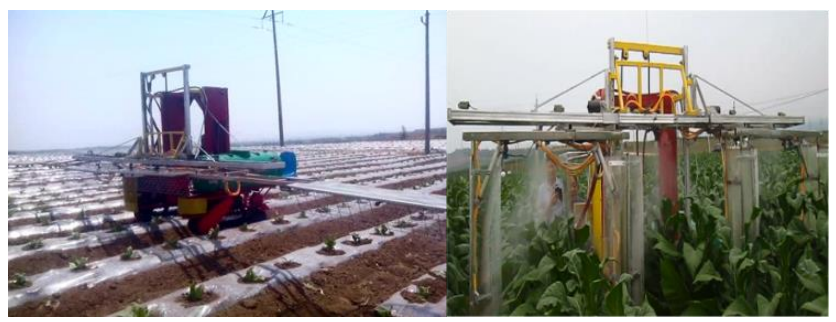

Fig. 5. Field test cases of multifunctional sprayer

Field test data was shown in Table IV. It showed that multifunctional sprayer could meet the needs of spraying control in different growth stage of tobacco. And the sprayer had high efficiency, almost no damage to tobacco leaves, better liquid coverage and machine utilization.

TABLE IV. FIELD TEST DATA

\begin{tabular}{|c|c|c|c|c|c|c|c|}
\hline \multicolumn{4}{|c|}{ Boom spray system (Seedling stage) } & \multicolumn{4}{|c|}{ Tunnel spray system (Maturity stage) } \\
\hline $\begin{array}{l}\text { Operating } \\
\text { width }(\mathrm{m})\end{array}$ & 8.4 & $\begin{array}{c}\text { Nozzle } \\
\text { spray } \\
\text { angle }\left({ }^{\circ}\right)\end{array}$ & 110 & $\begin{array}{l}\text { Operating } \\
\text { width }(\mathrm{m})\end{array}$ & 3.6 & $\begin{array}{c}\text { Nozzle } \\
\text { spray } \\
\text { angle }\left({ }^{\circ}\right)\end{array}$ & 80 \\
\hline $\begin{array}{c}\text { Walking } \\
\text { speed }(\mathrm{m} / \mathrm{s})\end{array}$ & 0.47 & $\begin{array}{c}\text { Spraying } \\
\text { amount } \\
\text { per acre } \\
\text { (L) }\end{array}$ & 30.86 & $\begin{array}{c}\text { Walking } \\
\text { speed }(\mathrm{m} / \mathrm{s})\end{array}$ & 0.53 & $\begin{array}{l}\text { Spraying } \\
\text { amount } \\
\text { per acre } \\
\text { (L) }\end{array}$ & 75.8 \\
\hline $\begin{array}{c}\text { Spray } \\
\text { distance } \\
(\mathrm{m})\end{array}$ & 0.45 & $\begin{array}{l}\text { Working } \\
\text { efficiency } \\
\left(\mathrm{hm}^{2} / \mathrm{h}\right)\end{array}$ & 1.225 & $\begin{array}{c}\text { Spray } \\
\text { distance } \\
(\mathrm{m})\end{array}$ & 0.35 & $\begin{array}{l}\text { Working } \\
\text { efficienc } \\
\text { y }\left(\mathrm{hm}^{2} / \mathrm{h}\right)\end{array}$ & $\begin{array}{c}0.68 \\
7\end{array}$ \\
\hline $\begin{array}{c}\text { Leaves } \\
\text { liquid } \\
\text { coverage } \\
(\%)\end{array}$ & 89.7 & $\begin{array}{l}\text { Leaves } \\
\text { damage } \\
\text { rate }(\%)\end{array}$ & - & $\begin{array}{c}\text { Leaves } \\
\text { liquid } \\
\text { coverage } \\
(\%)\end{array}$ & 92.8 & $\begin{array}{l}\text { Leaves } \\
\text { damage } \\
\text { rate }(\%)\end{array}$ & $\begin{array}{c}0.01 \\
2\end{array}$ \\
\hline
\end{tabular}

\section{CONCLUSIONS}

1) In different growth stage after tobacco transplanting, multifunction sprayer could select a different spraying mode based on plant morphology, to conduct boom spray to seedling growth stage, and to conduct tunnel spray to maturity growth stage.
2) The frequency deviation of deformation mechanism between finite element modal analysis and modal test was less than $10 \%$ could meet the design requirements.

3) By ANSYS finite element modal and dynamic simulation of ADAMS analysis, sectional dimensions of horizontal sliding frame, flank spray frame rails and stanchions after optimized was $25 * 35,25 * 35$ and $20 * 20 \mathrm{~mm}$ respectively, wall thickness was 2,2 and $1.5 \mathrm{~mm}$ respectively.

4) In tunnel spray test of tobacco maturity stage, the leaves liquid coverage reached $92.8 \%$, and almost no damage to tobacco leaves.

\section{ACKNOWLEDGMENTS}

This work supported by the National Natural Science Foundation of China (No. 51475278), Shandong Science and Technology Development Project (No. 2014GGB01483 and 2013GNC11203) and Shandong Provincial Agricultural Equipment Research and Innovation Projects (Grant No. 2015YB201).

\section{REFERENCES}

[1] X. C. Dong, T.W. Qing, L. M. Liu, Effects of different chemicals and application methods on controlling alternaria alternata . Hubei Agricultural Sciences, 07, pp. 1630-1632, 2010.

[2] H. Z. Yuan, D. B. Yang, X. J. Yan, Pesticide efficiency and the way to optimize the spray application. Plant Protection, 37 (5), pp. 14-20, 2011.

[3] X. J. Yang, H. R. Yan, X. S. Zhang, Current situation and development trend of equipment for crop protection. Transactions of the Chinese Society for A gricultural Machinery, 33 (6), pp. 129-131, 2002.

[4] C. Feng, CH. SH. Zhang, J. Wang, Comparison of different vaporizers for the evaluation of pesticide efficacy in tobacco field. Chinese Tobacco Science, 01, pp. 52-55, 2011

[5] F. Dieter, G. P. Jan, N. David, Spray deposition and distribution in a bay laurel crop as affected by nozzle type, air assistance and spray direction when using vertical spray booms, Crop Protection, (41), pp. 77-87, 2012.

[6] B. Wang, D. X. Zhang, L. Yang, High frame corn sprayer door spray system. Transactions of the China Society of Agricultural Engineering, 45(6), pp. 104-111, 2014.

[7] X. L. Lv, X. M. Fu, L. Wu, Influence of spray operating parameters on droplet deposition. Transactions of the China Society of Agricultural Engineering, 42(6), pp. 70-75,2011.

[8] P. Wang, L. J. Qi, H. Li, Influence of plant leaf surface structures on droplet deposition. Transactions of the Chinese Society for Agricultural Machinery, 44(10), pp. 75-79, 2013.

[9] P. Gianfranco, G. Rino, R.S. Sirio, Assessment of spray deposition and recycling rate in the vineyard from a new type of air-assisted tunnel sprayer, Crop Protection, (45), pp. 6-14,2013.

[10] B. J. Qiu, Y. J. He, Y. H. Shen, Finite Element Modal Analysis and Structure Optimization of Spray Boom. Transactions of the China Society of Agricultural Engineering, 45(8), pp. 112-116, 105, 2014. 